\title{
Exploring an Experience of Active Learning in Higher Education
}

\author{
Marta Mendonça (Corresponding author) \\ Eduardo Mondlane University, Faculty of Education \\ PO Box 257, Maputo, Mozambique
}

Tel: 258-82-3290-270Ｅ-mail: marta.mendonca@uem.mz

Gun-Marie Frånberg

Department of Applied Educational Science

Faculty of Social Science, Umea University

SE-901 87 Umea, Sweden

Tel: 46-7866-205 E-mail: gun-marie.franberg@edusci.umu.se

Received: December 31, 2013 Accepted: February 7, 2014 Published: February 20, 2014

doi:10.5296/jet.v1i2.5153 URL: http://dx.doi.org/10.5296/jet.v1i2.5153

\begin{abstract}
This article presents a subjective experience of attending a pedagogical training course for higher education teaching staff at Umea University, in Sweden. A participant observation was carried out based on an inductive approach. Data were collected through reports done in form of narratives at the end of each session. The analysis was done by critical reflection and the narratives were selected and thematically grouped according to the activities carried out during the course. Further, the analysis was supported by relevant literature related to educational theories that sustain student's accountability in learning and interactive classes. The results of the study conclude that the role of the teacher is crucial to make students active, motivated and self-regulated. However, students' active learning also depends on other factors such as contextual, social and psychological aspects. In addition, the communication involved in the process of teaching and learning develops confidence, empathy and achievement of good academic results.
\end{abstract}

Keywords: active learning, communication, experience, higher education, self-regulation 


\section{Introduction}

In order to obtain a better understanding of what active learning in higher education means, a study was carried out at Umeå University in Sweden. The researcher herself attended a course named Supporting learning at the Centre for Teaching and Learning, [Universitetspedagogiskt Centrum, UPC]. This article reports on this experience, but also on the role of the facilitators, participants and the feelings of the researcher participant acting as a student. The target group of the course was university teachers, researchers and doctoral students from Umea University, a total of 24 participants. The aim of the course was to enhance the understanding of teaching and learning at university level but also to increase participants' abilities to develop their learning through reflection and discussion about students' and teachers' roles in the process of teaching and learning. The activities of the course were organized from March to June 2011, consisting of 6 days of seminars and 4 days of participants' activities, distributed in individual, pair or group work.

The aim of this article is to make the researcher's own personal experience as both a student and a university teacher visible and to reflect on the processes of teaching and learning, particularly in higher education. This will be done, firstly, by reflecting and discussing potential characteristics of an active learning situation and secondly, to present the different approaches to teaching and learning used during the course of study.

Several new studies have been carried out with the aim of highlighting the concepts of teaching and learning. Harland (2012) points out that to realize the purposes of teaching, and consequently what can be achieved in academic work, a systematic exploration of the ideas and pedagogical conditions for their implementations are required. In this regard, curriculum can be understood as task, activity, interaction and discourse in the classroom (Alexander, 2012).

Some concepts were particularly important for the study. Active learning is a frequently used concept in education. It refers to several models of instruction that focus on the responsibility of the learners in learning. In this regard, the teacher's job is to move students from memorizing into a more active mode of learning in which the student seeks to construct conceptual meaning and thus understand the subject matter at a deeper level (Harland, 2012).

The concept of reflection is also often used in academia, since it can provide a relatively confidential way to explore and express experiences that otherwise might be difficult to communicate (Bolton, 2009). Davis (2003) asserts that a reflective practice leads to better learning. She also stresses that reflection challenges assumptions, ideological illusions, damaging social and cultural bias, inequalities and questions personal behaviors, which perhaps silence the voices of others or otherwise marginalize them.

Bolton (2009) also clarifies the difference between reflection and reflexivity by emphasizing that a reflective practice is purposeful and dynamic. In this regard, it opens up a developmental reflective and reflexive space. According to the author a reflective practice can enable practitioners to learn from experience about themselves, their work and wider society and culture. Thus, reflection is an in-depth consideration of events or situations 
outside oneself. Reflexivity, on the other hand, is according to Bolton (2009) to find strategies to question our own attitudes, thought processes, values, assumptions, prejudices and habitual actions and to strive to understand our complex roles in relation to others.

Hence, in order to reflect on the process of teaching and learning, the following research questions were posed in the study:

1) What characterizes the participants' and facilitators' role in the course Supporting learning?

2) What are the feelings and experiences of the researcher-participant in the course?

\section{Theoretical Perspectives on Active Learning}

The study referred to in this article, takes its starting point in an ethnographic approach since the social interaction and social and cultural aspects of learning are taken into consideration. The researcher herself is part of the process she is studying. The study is also based on theoretical perspectives that consider students as active agents in the process of learning. One of the theories that underpin active learning is constructivism, which is based on the idea that each learner actively constructs new knowledge through their own experiences and what they already know (Harland, 2012).

Another perspective on the process of learning is related to the sociocultural approach based on Vygotsky's theory. One concept that is central in this theory is the notion of the zone of proximal development (ZPD) that conceptually focuses on the dynamic relationship between collaborative learning and development. Vygotsky also claims that social interaction plays a fundamental role in learning. Consequently, communication can be considered as central to the relationship between the learner and others in the social world. Mercer (2004) following Vygotsky's line of thought points out that communicative events are shaped by cultural and historical factors. Thus, thinking, learning and development cannot be understood without taking into account the intrinsically social and communicative nature of human life.

In this regard, research seek to understand how learners adapt to dynamic contexts by constantly developing their skills. Zimmerman and Schunk (2001) point out that self-regulated students view learning as an activity that they do for themselves in a proactive way and is a result of teaching experiences, personal initiative, perseverance and adaptive skill in pursuing it, where social forms of learning can be included. Zimmerman (2001) asserted that self-regulated students are meta-cognitively, motivationally and behaviorally active participants in their own learning process. Hence, the concept of self-regulated learning (SRL) encompasses four dimensions: Firstly, the students' self-generated thoughts, feelings and actions to attain their learning goals. Secondly, the students monitor the effectiveness of their learning methods, strategies and respond to the feedback from covert or overt changes in self-perception, replacing one learning strategy to another. Thirdly, related to the motivational dimension, a description of how and why students choose to use a particular self-regulated process, strategy or response is needed. Finally, it requires the student to use additional preparation, time, vigilance and effort. 
In this study, in addition to educational theories related to the process of teaching and learning and social interaction in the classroom, the first dimension of SRL, i.e. students' self-generated thoughts, feelings and actions to attain their learning goals, is explored since the focus is on the role of the facilitators and participants.

The facilitators of a course establish and judge the standards for improving the effectiveness of an educational practice (Light, Cox, \& Calkins, 2009). With this in mind, the authors emphasize that development programmes aim to help practitioners to identify, critically examine and develop expertise and skills in relevant practices embedded in their own discipline, department and institution.

\section{Method}

A qualitative method based on participant observation was used. Accordingly, the researcher participated actively in the course Supporting Learning for ten days, spread out between March and June 2011, in order to learn about the contents of the course and also to experience what it means to be a participant in a pedagogical in-service course at Umeå University. The data collection started when the facilitators informed the participants that they had been selected for the course. It was no admission requirement to the course, but the number of participants was limited. In this regard, the facilitators and participants' roles were firmly established. For instance, participants were requested by email to access the course website and read the course learning objectives and assignments before the course start. This early communication helped the researcher to reflect in action on the different roles and also to start planning the course's activities. Mercer (2004) points out that a dialogic process means to reflect on the values and social practices of schools as cultural institutions. Also Zimmerman (2001) stresses that guidance helps students to be self-regulated.

Different perspectives on learning were treated in the course, such as, knowledge and learning, difficult teaching situations, teaching with a gender perspective, student active learning, language and learning, peer-learning, problem-based learning, learning and laboratory practice, and plagiarism, cheating and learning. The process of learning, particularly on student active learning, was of great interest in this study.

All tasks requiring activity from the participants were considered and underlined in a notepad from the start until the end of the course. This means that the researcher can be seen as "an insider" (Cohen, Manion, \& Morrison, 2000, p. 54). An insider generally is a member of the organization where the research is taking place. Thus, the researcher gets insights into cultures and events coming from experiences in the daily life of the people under study, either openly in the role of a researcher or covertly in some disguised role (Denscombe, 2007).

In this study, the researcher behaved naturally as an active participant, and the fellow colleagues didn't discover the researcher's role. Nevertheless, it is important to mention that at the start of the course, the researcher revealed her desire to the facilitators to write this article at a later date, and they gave their permission. The reports/narratives were made at the end of each session, summarizing all activities carried out during the seminars. The structure of data collection was thus built along the process of the course. 
The concept of narrative, according to Riessman (2008) carries many meanings and is used in a variety of ways by different disciplines, often synonymously with a story. Events perceived by the writer as being important are selected, organized, connected and evaluated as meaningful for a particular audience. In this sense, personal narratives encourage others to act and change, to promote empathy across social locations. Narratives can thus be perceived as strategic, functional, and purposeful. In the same thread of thinking Coffey and Atkinson (1996) state that narratives are temporal and logical, because as a story of a sequence of events they have significance for the narrator and his or her audience.

The analysis of the data material was done reflectively and based on an inductive approach, taking into account the aspects that characterize the organization of a course or the structure of a lesson such as "procedures", "relationship" and "goal" (Alexander, 2012, p. 15). In this process, the social perspective of learning was considered. For instance, data from observations and all activities carried out, including the experience of the researcher during the course helped in the selection, labeling and grouping of the narratives thematically. The activities were summarized and analyzed according to the role of the participants and the role of the facilitators during the course. Themes were identified with the aid of educational theories of teaching and learning, i.e. constructivism, socio-cultural theory and theories of self-regulated learning that underline the student's responsibility in the process of knowledge construction and emphasize what can be the role of students and teachers in an active learning situation. Harland (2012) proposed that learning theories have the power to be explanatory, in the sense that they predict cause and effect and thus are open to debate.

In order to strengthen the validity further, a research seminar was arranged where the study was presented and discussed. Some of the participating researchers had attended similar courses, and their comments were of great value. Also Bishop and Shepherd (2011, p. 1283) assert that "being reflexive and providing these reflections for public scrutiny is often considered a key element of ethical, rigorous qualitative research".

According to Boyatzis (1998) an inductive method is about the process of developing a thematic code that is data-driven and telling stories about one's past experiences and events, as a method of communicating emotions, transmitting cultural values, and creating history. Accordingly, he asserts that a theme describes and organizes possible observations or at the minimum interprets aspects of the phenomenon. Also, Boyatzis (1998, p. vii) underlines that "the themes may be initially generated inductively from the raw information or generated deductively from theory and prior research".

\section{Results}

The results are presented according to the following themes identified in the process of data analysis: Preparing the learning environment, The process of learning and The process of assessment. These themes will be developed below and supported by examples from the narratives.

\subsection{Preparing the Learning Environment}

First of all, the aim of the course was to enhance the participants' understanding of teaching 
and learning at university level and to increase participants' ability to develop their own teaching (Umeå University, 2011). Hence, the course was basically related to the ways in which teachers usually carry out their teaching and students learn. In this context, activities were planned in order to make it possible for participants to reflect on and discuss their own practices in the classroom. Therefore, before the course started the list of participants, the schedule (time and place), learning objectives, the contents of the course, teaching strategies, course literature and individual assignments, were sent to the participants. Thus, the first learning activity was:

Read the course learning objectives and assignments; write down some lines, preferably in bullet form... about how you think upon learning... describe a problem situation related to this and post it in the forum.

Readings for the following days were also specified. In fact, it was a starting point for reflection on my own style of learning and at the same time on my style of teaching. These two processes are strongly interconnected. The first question that appeared in my mind, as a student was "Is this course important to me?" "How can I apply this knowledge in my academic life in Mozambique?" "What is the importance of this knowledge for the improvement of my teaching?"

On the first day of the course all participants' seats were already fixed with our names written on a piece of paper on the table. I asked myself, why? The answer came early, when a participant tried to change their place, shifting the name. Suddenly the facilitator shouted:

"No!" "We have a plan with this organization!"

It was really amusing! In fact, they had already designated a "critical friend" for each participant. For instance my critical friend was from "Handelshögskolan, USBE", which means Umea School of Business Education. After this, each participant introduced himself or herself and was requested to talk about something that was related to his or her first experience of teaching. It was a funny and interesting moment when each one tried to remember how fearful and exciting it was and at the same time to see where we are now. The exercise was a kind of confession of our failures and duties as teachers and at the same time to see our progress in teaching. After the two days, during an oral course evaluation a participant disclosed very concerned:

"I am disappointed with myself... I will review my teaching style".

Summing up, some methodological approaches can be identified in this theme such as peer interaction, group work, presentation and discussion that supported participants' social learning and inner reflection in the process of teaching and learning.

\subsection{The Process of Learning}

During the course, I could recognize that the activities were planned with minimum details in order to meet participants' needs. In this sense, the strategies adopted were a combination of course and workshop, where interaction and communication with peers or among all participants was valued. Guests were invited to present specific themes related to the content 
of the course.

I could understand the importance of reading the materials on time, because each of us should give his or her contribution during the group work and discussions. This meant that participants learnt from fellow colleagues, readings, guests and facilitators. The role of the facilitators was to moderate the discussions, provide feedback, control time, prepare and propose activities as well as guide participants' assessment and course evaluation.

Group work, presentations and discussions were always "hot". The questions posed always required personal experiences and this aspect encouraged participants to talk. For instance, in one of the sessions the issues discussed were:

"What models of teaching are related to your own situation as a teacher"? Or

"What is a good lecture"?

Related to gender participation during the presentations and discussions, I could observe that female participants were much more talkative than male. Regarding this behaviour, it is the opposite in my own context as a lecturer in an African country. Most of the time, it is necessary to request female students to comment or reflect about what is being presented or discussed.

Another learning situation that caught my attention and that I have underlined in my notes was the theme "cheating and plagiarism" and the way the facilitators introduced this to the participants. In my context cheating and plagiarism is still rather common and teachers seldom report it. In this sense, it was somewhat challenging to feel "tested." This issue evoked my thoughts about what values I relate to this matter. I also felt a duty to discuss this matter with my students and colleagues in Mozambique, in order to develop some values that could be useful in their lives. The related course activity was posed in this way:

The facilitators requested that we emptied the tables and then each participant received an envelope with an exercise that consisted of making a square from the different pieces of paper provided. The participants were not allowed to talk to each other but could share the pieces of paper that were not useful for building his or her square. The exercise was considered done when all participants from the group had completed building their square. Then the group left the room and the "checker" told us if the rules had been broken or not by somebody.

At the end of the session documents were distributed to the participants, including university rules about cheating and plagiarism.

During the course sessions I experienced several strategies of learning, for instance, role-play and problem based learning (PBL). I have heard before about these strategies but as a teacher I never tried them with my students. Maybe I was not confident to try new pedagogical methods.

Most of all, what astonished me was the group work. As a teacher I do always plan group work for my students. During the course we were trained how to motivate students to be 
more committed in such kind of activity. For instance, it was suggested to recommend the group to make a list of what they should do and what they should not do. This involves making a contract to follow before the assignment starts. This procedure allows students to be responsible and committed to the common task. In case of conflict they can return to the contract and check what they have previously agreed on.

Summing up, in this theme, the development of participants' reflection on the teachers' role in the development of students' values, such as justice and accountability, and reflection on the process of their learning, can be highlighted.

\subsection{The process of Assessment}

In this theme I would like to describe my involvement in the process of assessment that was the last activity carried out in the course. It dealt with the summative assessment of the course performance of my fellow colleague. Suddenly I found myself with the responsibility of commenting on my critical friend's final assignment. It was a challenge to show to everybody the coherence of my analysis, because I was being assessed as well.

A formative assessment and partial course evaluation was carried out throughout the course. In this sense, the formative assessment consisted of presentations and discussions, followed by the facilitators' comments after group work. The summative assessment consisted of individual assignments that on approval led to a course certificate. The assessment consisted of two tasks. The first one was:

\section{A description of a teaching situation from your own working environment with an accompanying reflective conversation with a critical friend from the course group.}

In fact, it was difficult to decide what teaching situation I could describe, because in my mind there were lots of concerns that appeared like a "cascade". Finally I decided to share with my critical friend my dilemma related to cheating and plagiarism that is a huge problem in my own working environment. I felt surprised to notice that at Umea University this is no longer a problem because students are familiar with the rules about it and they avoid such kinds of situations. To my amazement, I could read the "shock" also in the face of my critical friend during my presentation. However, this issue is still a huge problem in my teaching reality.

The second assignment consisted of:

The formulation of your own pedagogical approach, "The way I want to work as a teacher to support the learning of students". Your own pedagogical approach shall be presented orally and written on the final day of the course. The documentation can be a part of your own professional teaching portfolio.

I gave myself the pleasure of dreaming of a pedagogical approach "utopia" where all conditions were available to put in practice all the learning situations discussed during the course in order to develop my students critical thinking and values that could help them in their lives. However, I soon realized that many contextual factors related to the poverty of my 
country could hinder this dream.

In this theme, the importance of students' involvement in their own process of assessment can be underlined in order to develop their consciousness, fairness, justice, empathy and above all, the responsibility of the self-regulation of their learning.

\section{Discussion}

Going back to the first research question "what characterizes the participants and facilitators' role in the course "Supporting learning", the findings show that in relation to the theme "Preparing the learning environment" the tasks were directed towards reflection and social forms of learning at an early stage. The participants were also requested to think about learning and share their experiences, through presentation and discussion about their own educational practices. Therefore, the facilitators guided and provided feedback based on the standards for improving the effectiveness of educational practices. Thus, it can be stressed that the role of the facilitors was crucial for increasing participants' interest and performance on the course.

In this regard, the communicative approach was as Mercer (2008, p. 358) points out "interactive/ dialogic" and "non-interactive dialogic". This means that the teacher might ask students to elaborate their ideas, but the teacher would not make evaluations of these ideas in terms of correctness. The teacher would not lead discussions, but would record ideas on the board for future reference, or ask students whether they agree or not to what has been said.

Further, Alexander (2009, p. 11) states, "pedagogy does not begin and end in the classroom". Accordingly, he defines pedagogy as the observable act of teaching, combined with the discourse of educational theories, values, evidences and justifications. Harland (2012) underlines that Bloom's Taxonomy of Educational Objectives can help to determine what to teach, how to teach and how to grade in order to describe the range of educational possibilities for learning. Here, I will also refer to Grohs and Tech (2012) assertion that instructors must design reflection activities that promote students' own awareness. Further, that students should know what is coming up in the lecture, in order to allow them to connect with what they already know and can do. In this regard, Harland (2012) claims the lecturer needs to create a learning environment, if he or she wants the learner to reflect or think critically. Thus, if the primary goal is generating interest then attention should be paid to the opening sequence, using high quality aids and lively, perhaps intriguing examples (Brown \& Atkins, 1988).

The findings also indicate that contextual factors influence the process of teaching and learning. According to Daniels, Lauder and Porter (2009) teaching is located in a larger cultural context, but students and teachers create their own microculture. In this regard, teaching has structure and form, and is situated and governed by space, time, patterns of pupil organization and a purpose. Thus, a lesson is part of a larger curriculum embodying purposes, values, and reflecting assumptions about what knowledge and understanding are of most worth to the individual and to the society. Since students use a variety of approaches to learning, lecturers can approach their teaching in different ways creating conditions for a 
constructive dialogue, when selecting any organizational mode (Harland, 2012). For the reasons pointed out above, "good teaching and engagement with students is tiring" (Franghanel, 2012, p. 51).

The role of the course' participants was, on the other hand, to put teaching in relation to our own experience, to discuss together with a critical friend, to document our own pedagogical approach and give feedback to the pedagogical approaches of our colleagues. This social interaction and feedback from peers helped us to better understanding the assignments and also the concepts discussed in the seminars. According to Vygotsky's theory the role of guidance or collaboration with more capable peers is essential for attaining a higher level of development, within the so called Zone of Proximal Development. During the course we were also supposed to observe a lesson taught by our critical friend and together discuss the steps of the lesson.

A critical friend according to Handal, (1999, p. 65) "is a person whose viewpoints are respected, who is listened to, and who can serve as a role model". Hence, all activities suggested required a high capacity for communication, analysis and reflection, always related to individual experiences. Grohs and Tech (2012) even state that reflection that remains disconnected from personal motivations can be dangerously hollow.

Gender considerations in pedagogical planning were also discussed. In relation to the course, I perceived that gender behavior varied during group discussions and presentations. For instance female participants were significantly active in all activities during the course. In contrast, in my own cultural context, women generally don't talk too much. This means that, cultural factors are often reproduced in the academe and female students often avoid giving their opinion, and become passive.

Related to the second research question: "what are the feelings and experiences of the researcher participant in the course", I would like to highlight two aspects: first of all, related to my feelings as a course participant and secondly to my position as a university teacher. As a course participant, I could understand that it is a huge responsibility and very demanding to become an active learner. To be active means to be organized, to access the literature and actively read all materials on time, to be able to work with others and meet deadlines. I realized that the only way to arrange my different roles as a course participant and researcher toward my goals better, was to avoid procrastinating activities and underline priorities in my schedule. According to Corno (2001, p. 205) "procrastinators postpone their intentions to study with little guilt".

During the course, the participants were supposed to be active and metacognitive in the process of learning. Being a metacognitive student means to be able to evaluate one's own knowledge and learning (Garner, 1990). In relation to this, I feel that my "learning behavior" became different in Umea from my previous educational experience in Mozambique. In Umea we had transparent course goals and clear communication channels. For instance, from the start, a good communication with facilitators was established by email in order to provide the materials of the course, for instance, the schedule, literature, instructions and assignments. Also, contextual factors such as an up-to-date library and easy access to internet, helped me 
to plan and self- regulate my process of learning. Discussion with fellow colleagues also helped me to learn more from different points of view. Mercer (2008) and Zimmerman (2001) stress the significant role of dialog and social interaction in educational practice, including modeling, guidance, and feedback from peers, coaches and teachers.

The second aspect deals with me as a university teacher. It was obvious that a teacher has to play the role model in terms of self-organization. I perceived that a good preparation of the course activities increases student's motivation for learning. For this reason, the role of the teacher when it comes to the development of students' motivation, confidence and awareness related to their learning is crucial for the enhancement of knowledge, skills, critical thinking and social values.

In the findings, situations related to cheating and plagiarisms were reported. In this regard, McKeachie (1994) shows that providing a number of opportunities for students to demonstrate achievement of course goals, rather than relying upon a single examination, making reasonable demands, writing reasonable and interesting tests and developing group norms that support honesty, could help to prevent this kind of concerns.

\section{Conclusions}

Finally I want to present some conclusions drawn from the study. First of all, to be a researcher participant was demanding, considering that in this study only the facilitators were informed about the researcher and participant's roles. Thus, the "naturalness of the setting" should be preserved for the participants (Denscombe, 2007, p. 218). The limitation faced was on the one hand, the dependence on the field notes for data collection, which demanded double attention, on both the participant and researcher roles. On the other hand, there was a challenge to meet the requirement to analyze the results impartially, avoiding bias. Bolton (2010, p. 253) underlines that a reflective practice means "an open questioning mind".

As a teacher, and according to my own experience, the results made me conclude that, to develop an approach of active learning in higher education, a good preparation of the process of teaching and learning, as well as the availability of resources are crucial. For example, through good communication, using all necessary supplies, guidance and collaboration, the learners could actively participate in the construction of their knowledge. Vygotsky's theory emphasizes social interaction as a key to learning. The results also showed that the context of learning is decisive to support the process of knowledge achievement. In this respect, following Mercer (2004), learning and development cannot be understood without the intrinsically social factors, the nature of communication and cultural history of human life. Being an active learner also means to communicate with classmates and teachers, in order to monitor and self-regulate the learning process (Zimmerman, 2001).

Moreover, the study gave me an opportunity to reflect on the meaning of assessment. According to Boud (2000) assessment has two purposes, namely, certification (summative assessment) and improving learning (formative assessment). In this sense, communication with students about the kind of assessment that will be done is important for the development of students' confidence, accountability, empathy and will in achieving good academic results. 
"Assessment acts need both to meet the specific and immediate goals of a course as well as establishing a basis for students to undertake their own assessment activities in the future" (Boud, 2000, p. 151). I see this as a challenge, to introduce my students in Mozambique to this way of thinking about assessment and self-regulation.

\section{Acknowledgement}

The research is financed by Sida - Swedish International Development Cooperation Agency with Eduardo Mondlane University, Mozambique.

\section{References}

Alexander, R. (2009). Pedagogy, culture and the power of comparison. In H. Daniels, H. Lauder \& J. Porter (Eds.), Educational theories, cultures and learning: A critical perspective (pp. 10-26). USA: Routledge.

Bishop, E. C., \& Shepherd, M. L. (2011). Ethical reflections: Examining reflexivity through the narrative paradigm. Qualitative Health Research, 21(9), 1283-1294. Retrieved February 15, 2014, from http://www.ncbi.nlm.nih.gov/pubmed/21508253

Bolton, G. (2010). Reflective practice: Writing \& professional development. London: SAGE Publications Ltd.

Boud, D. (2000). Sustainable assessment: Rethinking assessment for learning society. Studies in Continuing Education, 22(2), 151-167. Retrieved February 15, 2014, from http://dx.doi.org/10.1080/713695728

Boyatzis, R. E. (1998). Thematic analysis and code development: transforming qualitative information. USA: Sage Publications.

Brown, G., \& Atkins, M. (1988). Effective teaching in higher education. London: Routledge.

Coffey, A., \& Atkinson, P. (1996). Making sense of qualitative data: Complementary research strategies. USA: Sage Publications.

Cohen, L., Manion, L., \& Morrison, K. (2000). Research methods in education (5 ${ }^{\text {th }}$ ed.). USA: RoutledgeFalmer.

Corno, L. (2001). Volitional aspects of self-regulated learning. In B. J. Zimmerman \& D. Schunk (Eds.), Self-regulated learning and academic achievement: Theoretical perspectives (pp. 191-225). New York: Lawrence Erlbaum Associates.

Daniels, H., Lauder, H., \& Porter, J. (2009). From Plato to Monday morning. In H. Daniels, H. Lauder \& J. Porter (Eds.), Educational theories, cultures and learning: A critical perspective (pp. 1-6). USA: Routledge.

Davis, M. (2003). Barriers to reflective practice: The changing nature of higher education. Active Learning in Higher Education, 4(3), 243-255. Retrieved February 15, 2014, from http://alh.sagepubcom/content/4/3/243

Denscombe, M. (2007). The good research guide: for small-scale social research projects 
( $3^{\text {rd }}$ ed.).USA: Open University Press.

Franghanel, J. (2012). Being an academic. USA: Routledge.

Garner, R. (1990). When children and adults do not use learning strategies: Towards a theory of settings. Review of Educational Research, 60(4), 517-529. Retrieved February 15, 2014, from http://www.jstor.org/stable/1170504

Grohs, J. R., \& Tech, V. (2012). Carefully, thoughtfully exploring the "I" in reciprocity: Practitioner reflections in striving for self-authoring student-citizens. Journal of College \& Character, 13(3). Retrieved February 15, 2014, from http://journals.naspa.org/jcc/ $10.1515 /$ jcc-2012-1886

Handal, G. (1999). Consultation using critical friends. New Directions for Teaching and Learning, 79, 59-70. Retrieved February 15, 2014, from http://onlinelibrary.wiley.com/doi/10.1002/tl.7907/pdf

Harland, T. (2012). University teaching: An introductory guide. USA: Routledge.

Light, G., Cox, R., \& Calkins, S. (2009). Learning and teaching in higer education: The reflective professional ( $2^{\text {nd }}$ ed.). London: SAGE Publications Ltd.

McKeachie, W. J. (1994). Teaching Tips: Strategies, research, and theory for college and University teachers $\left(9^{\text {th }}\right.$ ed.). USA: D.C. Heath and Company.

Mercer, N. (2004). Sociocultural discourse analysis: analyzing classroom talk as a social mode of thinking. Journal of Applied Linguistic, 1(2), 137-168. Retrieved February 15, from http://www.equinoxpub.com/journals/index.php/JALPP/article/view/17970/14187

Mercer, N. (2008). Changing our minds: a commentary on 'Conceptual change: a discussion of theoretical, methodological and practical challenges for science education'. Cult Stud of Sci Educ, 3, 351-362. Retrieved February 15, from http://link.springer.com/article/10.1007\%2Fs11422-008-9099-8

Riessman, C. K. (2008). Narrative methods for the human sciences. USA: Sage Publications, Inc.

Umeå University (2011). Welcome to the Course Supporting learning: $29^{\text {th }}$ March-1 ${ }^{\text {st }}$ June. Centre for Teaching and Learning. Retrieved February 15, from http://www.upl.umu.se/english/education/courses/supporting-learning/

Zimmerman, B. J. (2001). Theories of self-regulated learning and academic achievement: An overview and analysis. In B. J. Zimmerman \& D. Schunk (Eds.), Self-regulated learning and academic achievement: Theoretical perspectives (pp. 1-37). New York: Lawrence Erlbaum Associates.

Zimmerman, B. J., \& Schunk, D. H. (2001). Reflections on theories of self-regulated learning and academic achievement. In B. J. Zimmerman \& D. Schunk (Eds.), Self-regulated learning and academic achievement: Theoretical perspectives (pp. 289-307). New York: Lawrence Erlbaum Associates. 


\section{Copyright Disclaimer}

Copyright reserved by the author(s).

This article is an open-access article distributed under the terms and conditions of the Creative Commons Attribution license (http://creativecommons.org/licenses/by/3.0/). 